\title{
Prevention Procedures to Contain COVID-19 Contagion in the First Italian Army Field Hospital
}

\author{
Mario Ciccotti ${ }^{1 *}$, Paolo Pagliaro ${ }^{2}$, Ilaria Peluso ${ }^{3}$, Fabio Benfenati $^{4}$, Diego Munzi ${ }^{5}$, Tommaso Sciarra ${ }^{5}$, Gennaro \\ Palermo $^{6}$, Maria Chiara Sorbo ${ }^{7}$ \\ ${ }^{1}$ Military Pharmaceutical Chemical Plant, Florence 50141, Italy \\ ${ }^{2}$ Department of Anesthesia and Resuscitation, Army Medical Center, Rome 00184, Italy \\ ${ }^{3}$ Research Centre for Food and Nutrition, Council for Agricultural Research and Economics (CREA-AN), Rome 00178, Italy \\ ${ }^{4}$ Department of Immunohematology and blood transfusion medicine, Army Medical Center, Rome 00184, Italy \\ ${ }^{5}$ Joint Veteran Center, Scientific Department, Army Medical Center, Rome 00184, Italy \\ ${ }^{6}$ Chief Operating Room, Army Medical Center, Rome 00184, Italy \\ ${ }^{7}$ Scientific Department, Army Medical Center, Rome 00184, Italy
}

Corresponding Author Email: mario.ciccotti@aid.difesa.it

https://doi.org/10.18280/ijsse.110405

Received: 7 January 2021

Accepted: 16 July 2021

\section{Keywords:}

coronavirus, field hospital, PPE-Disinfection, COVID-19, pandemic, protocols

\begin{abstract}
The COVID-19 outbreak in Italy saturated the public hospitals' intensive care units in March 2020. The Ministry of Health asked for the Military Health Unit's intervention to deal with the emergency. The first COVID-19 Army field hospital in the world was thus built in Piacenza, Italy, to address the emergency. We describe the architecture of the hospital and the preventive measures adopted to reduce COVID-19 contagion among the medical personnel. The hospital project with the "H" shape divides the "dirty path" of entry for operators and patients from the "clean path" of exit for operators. Hypochloritebased and alcohol-based solutions were used for personal protective equipment (PPE) decontamination before reuse. Although exposed to 50 confirmed COVID-19 patients, all primary care personnel tested negative to COVID-19, before the operation, 14 days after the first patient and 30 days after the closure of the military field hospital. Due to the reported discomfort and its potential toxicity, the hypochlorite-based disinfection method was substituted with alcohol-based disinfection solution, which displayed comparable effective results. The results of the present study pave the way for the creation of a protocol for future validation in larger studies aimed at providing guidelines in emergency conditions.
\end{abstract}

\section{INTRODUCTION}

The 2019 novel coronavirus disease (severe acute respiratory syndrome coronavirus 2: SARS-CoV-2, or well known as COVID-19) [1] was declared by the World Health Organization (WHO) a global pandemic, on the 11th of March, 2020 [2]. It exploded in Italy, the first European country to be affected, at the end of February saturating briefly the intensive care not sufficiently organized to manage the large number of serious patient, which over time has increased from about $10 \%$ of total cases to about $5 \%$ of cases in need of intensive care (as of 06 April) [3]. SARS-CoV-2 is known today being the seventh coronavirus to infect humans causing severe disease [4]. Nonetheless the global commitment, the controversial opinions within the scientific community and the missing of clear and certain information about both the origin, the transmission [5-7], the state of incubation, the persistence [8] and the first reservoir and organ target of the virus $[9,10]$ rendered still difficult adopting focused, effective and definitive medical solution, that are continuously updated [11]. The criticality of the situation has required the intervention of the Military Health Department which built the first military field hospital "Role 2", in a bio-containment context. This structure, capable of accommodating 40 COVID-19 places, provided the support to the health facilities of the most affected city, Piacenza, $15 \mathrm{~km}$ away the origin village of outbreak, Codogno (Lodi) (Figure 1).

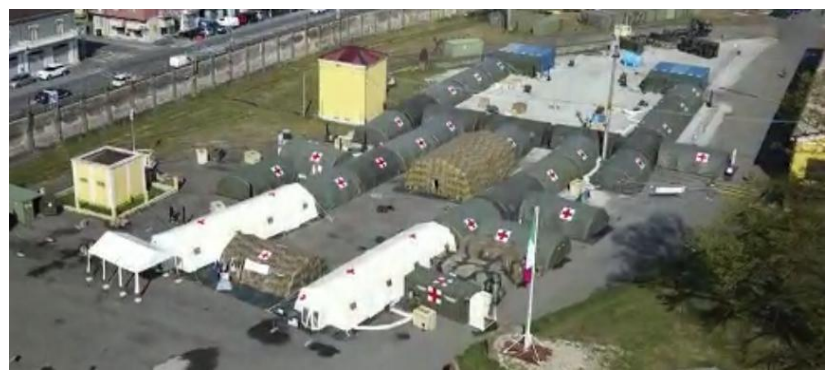

Figure 1. Picture of the area of the Army Field Hospital COVID-19 of Piacenza

Structure born as ROLE 2 to be used in the United Nation (UN) and North Atlantic Treaty Organization (NATO) missions as provided for by the NATO doctrine (NATO 2019) [12] and UN (United Nation 1999) [13] where different capabilities such as diagnostics, radiology, or laboratory analysis are provided, has been remodeled like the (United Nation 1999) [13] COVID-19 Field Hospital preserving: a 
pharmacy, a sub-intensive therapy with three beds, and hospitalization capacity for 40 COVID-19 places. The remaining activities such as diagnostics were carried out in collaboration with the Local Health Authority of Piacenza. Health care personnel have the potential for direct or indirect exposure to patients or infectious materials [14]. In this field scenario, the range of measures to be put in place to reduce the contagion of the pathology, through the adoption of appropriate disinfection protocols to ensure the killing of the virus and at the same time not excessively affect the comfort of health workers. The choice of procedures to be adopted in mitigating the risk of exposure to SARS-CoV-2 is impacting on the safety of the operator both for the psychological and for the biological risk reduction aspect. The mental approach of a healthcare worker, confident in the adequate preventing risk measures and conscious to access to an area with mitigated biological risk represents an advantage in terms of reducing the stress generated by the limitations imposed on the movement of personal protective equipment (PPE). The reduction of stress generated by the increased safety of the operator has a positive effect on the level of attention paid to the patient and the therapeutic procedures for the benefit of a higher quality of service in the broadest sense. The editors of JAMA "recognize the challenges, concerns, and frustration about the shortage of PPE that is affecting the care of patients and safety of health care workers in the US and around the world" [15]. While waiting for NATO to comply with specific directives, the protocols and procedures that have been hypothesized, in this paper we aim to report our experience that could be a starting point for subsequent improvements, especially in the field of military field hospitals COVID-19.

\section{MATERIALS AND METHODS}

\subsection{Paths of health professionals and patients}

In the design area, the modularity of the Hospital has also developed special paths that will be defined "dirty" when attended by COVID-19 personnel and "clean" when attended by non-COVID-19 personnel.

The structure under the tent has been built with ambient pressure without the use of negative pressure systems.

The first criterion analyzed is the construction self of the military field hospital, designed to create a distinction between the entry route in the presence of SARS-CoV-2, and the exit route without SARS-CoV-2 the operators, once dressed in the dressing tent, will enter the path in the presence of COVID-19 from the acceptance starting the "dirty path", they will finish their work passing from the reclamation tent to the dressing tent through the "clean path" (Figure 2).

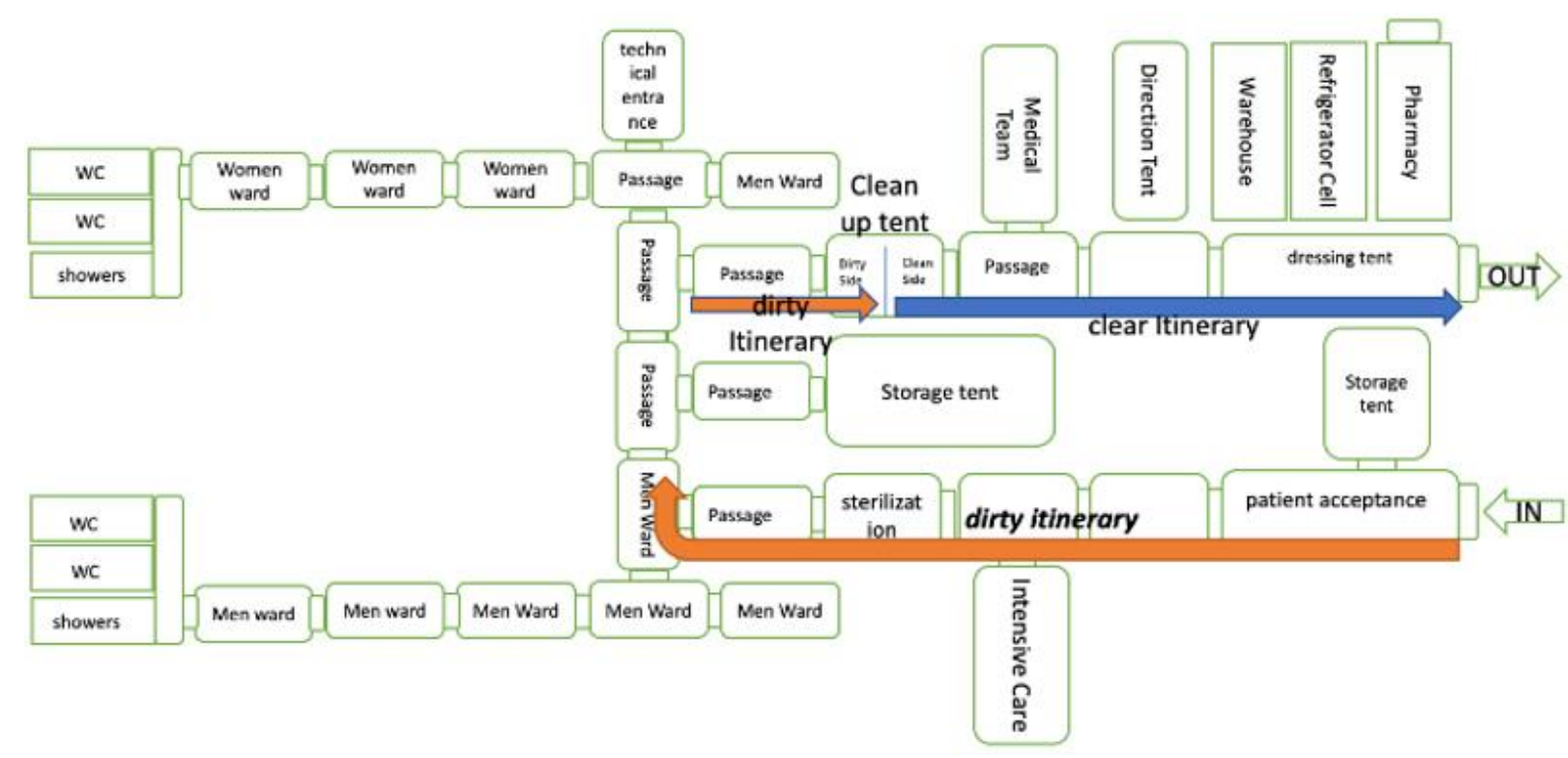

Figure 2. Planimetry of the hospital with the " $\mathrm{H}$ " shape. The "dirty itinerary" of entry for operators and patients is divided from the "clean itinerary" of exit for operators

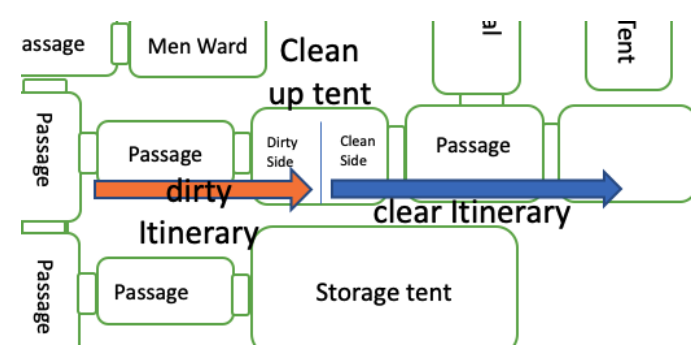

Figure 3. Detail of the disinfection of the "clean" and "dirty" zones. The mist sprayer with the $2 \%$ sodium hypochlorite solution is placed on the line that divides the clean zone from the dirty one
The "Clean up tent" represents the end of the dirty route and the beginning of the clean route. The tent is in turn divided into two parts by a line (Figure 3 ) placed on the base, the operators leaving the service will spray a $2 \%$ sodium hypochlorite solution on their PPE (in half of the dirty tent) and leave it for two minutes.

The solution was applied by means of an atomizer that was refilled with $2 \%$ sodium hypochlorite solution every day so as not to incur losses of title of the solution caused by the gaseous release of the molecular gas.

Once reclaimed, the staff moved to the other half of the tent where they undressed and placed the reclaimed PPE in special containers for disposal as biological waste. Reusable PPE, such as goggles, were placed in another container and at the 
end of the daily shift taken outside thanks to the container and subjected to a sanitization process with a special alcohol-based solution as explained below.

At the time of dismission, healed patients, abandoned the field hospital by crossing a direct path until the reception, in order to avoid passing through the clean-up tent.

They were accompanied by the health workers on duty, properly shielded by wearing all the provided PPE (Figure 4).

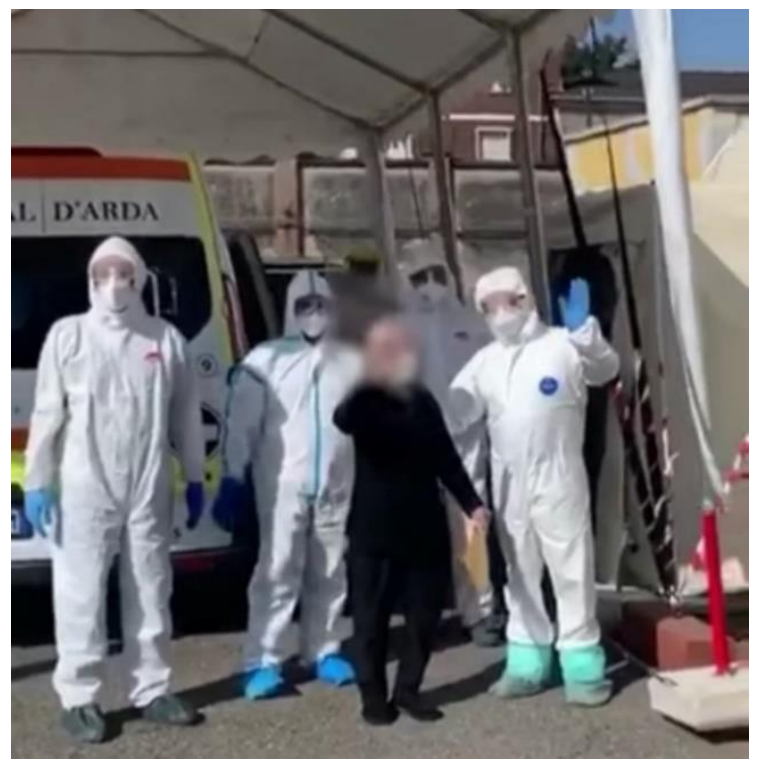

Figure 4. Operators from the Military Field Hospital of Piacenza who accompany the last patient discharged from the hospital to the exit of the dirty area

Once cured, patients were dismissed from acceptance and then they were transported by ambulance to their habitations.

\subsection{Materials leaving the dirty area}

Food and oxygen cylinders placed at the patient's head were brought in through the technical entrance, as well as the electro-medical material and unloaded medical oxygen cylinders, to be taken out of the hospital was taken out of reception after reclamation with $2 \%$ sodium hypochlorite nebulized on the surface and left for 3 days in quarantine in a special container before being used outside the hospital.

This type of design ensured the impossibility of any meetings between the staff entering the dirty area and the staff leaving the clean area, minimizing the possibility of SARSCOV-2 on surfaces where staff are not equipped with PPE.

The food and PPE residues used, and the drugs and medical devices used will be stored inside the biohazardous waste containers and will be cleaned externally, with $2 \%$ sodium solution nebulized externally, before collection by the company.

The plastic container, collecting the reusable PPE (goggles), was also cleaned externally once outside the hospital, where its contents underwent another disinfection process.

The wastewater leaving the toilets was collected in a special tank and disposed of with an appropriate authorized company.

\subsection{PPE and disinfection procedures}

For the reduction of biological risk from SARS-CoV-2 within the field structure, the applied measures consider both the necessary requirements to obtain the reduction of biological risk and the toxicological aspects aimed at safeguarding the personnel employed.

On the basis of the studies performed on the SARS-CoV-1 [16] and on the SARS-CoV-2 [17], that confirmed the virus permanence respectively in the environment and on surfaces and considering the related tests carried out with disinfectants aimed to cancelling the viral load of the virus [16], the following has been developed:

(1) for the disinfection of Tyvek suits and related PPE, at the end of the dirty path in the clean-up attempt, a $2 \%$ sodium hypochlorite solution was used this solution was sprayed with an atomizer and left to act for two minutes on the surface of the PPE of the operators;

(2) for the class III protective goggles disinfection and reuse, the WHO formulation produced by the Military Chemical and Pharmaceutical Plant in Florence, was adopted (80\% alcohol, 3\% hydroperoxide and purified water q.b.).

In the first case, the hypochlorite solution was left to act for two minutes on the PPE before being thrown into the appropriate containers for the hospital waste. The hypochlorite solution was renewed every day in order to maintain the chlorine concentration "at level", counteracting the phenomena of loss of concentration caused by molecular chlorine release.

In the second case, the protective goggles were cleaned with the WHO surface disinfectant solution, taking care to leave the goggles submerged for a period of 30 minutes. The goggles were cleaned once taken out from special containers in the clean-up tent for a total number of four treatments. Finally, they were disposed of as biohazardous waste together with the used PPE [16].

The choice to replace the sodium hypochlorite with the alcohol-based disinfectant for the disinfection of protective goggles, was made necessary to protect operators from intoxication. Indeed, a 5\% sodium hypochlorite solution used just for 10 minutes led to an erosion of the PPE and a subsequent release of molecular chlorine inside the masks during the operators' activity.

The choice of the alcohol-based solution was therefore rewarding in terms of comfort and prevention of side effects for the operators while not sacrificing biological safety. The solution used was changed every day to ensure the correct and optimal alcohol concentration.

The personal protective equipment used for each shift by the personnel employed inside the Military Field Hospital is described in the Table 1.

Table 1. Type and quantity of PPE employed

\begin{tabular}{cc}
\hline PPE & $\begin{array}{c}\text { Personal Quantitative } \\
\text { for shift }\end{array}$ \\
\hline Tyvek overalls with hood, & 1 piece \\
protection class III & 1 pair \\
Shoes covers, protection class III & 1 pair \\
Goggles, Class III & 2 pair \\
Nitrile gloves & 1 pair \\
Surgical gloves size 8 and $1 / 2$ & 1 piece \\
FFP2 protective masks without & filter
\end{tabular}

PPE, personal protective equipment.

Among the possible type of face masks (removing power of 0.3-micron particles), including N100 (99.97\%), FFP3 
(99.95\%), N95 (95\%), FFP2 (94\%), FFP1 (80\%) respirators and surgical masks (80\%) [18], personnel exposed to potential risk used FFP2 masks (Table 1); all health personnel doublechecked after wearing one with the other, the complete wearing is shown in Figure 4.

\subsection{Staff testing}

In order to verify the effectiveness of the measures, three swabs were carried out on the medical staff entering the military field hospital to verify the presence of SARS-CoV-2, with the following analysis protocols:

(1) Diagnostic detection of 2019-nCoV by real-time RTPCR-Protocol and preliminary evaluation as of Jan 17, 2020 -Victor Corman, Tobias Bleickerm Sebastian, BrÜnink, Christian Drosten, Charité Virology, Berlin, Germany.

(2) Diagnostic detection of Wuhan coronavirus-2019 by real-time RT-PCR - Protocol and preliminary evaluation as of Jan 13, 2020 - Victor Corman, Tobias Bleicker, Sebastian BrÜnink, Christian Drosten, Charité Virology, Berlin, Germany.

All staff were swabbed with two types of swabs (Figure 5), oropharyngeal and nasopharyngeal.

The material used is as follows:

- Test tube with UTM® culture medium brand COPAN

- FloQSwabs® brand COPAN

The swabs were performed before the arrival in Piacenza, 15 days after the first patient entered and 30 days immediately after the exit of the last patient. The last swab was also performed on the logistic staff of the base, with whom the medical staff interfaced in the logistic area for the entire duration of the mission and with whom they also shared the sleeping tents.

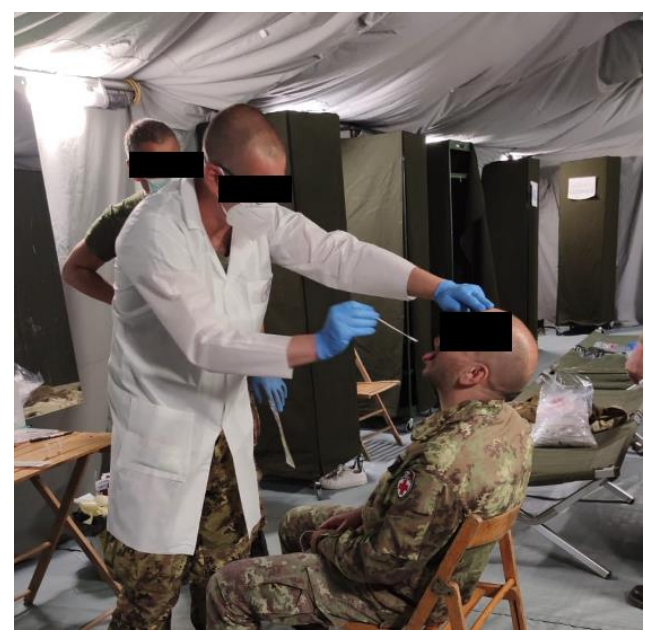

Figure 5. Oropharyngeal and nasopharyngeal swab to a healthcare worker

\section{RESULTS}

Within Military Army Hospital an average of 19 operators entered the area called "dirty zone" for 30 days for a total of 570 people exposed to SARS-CoV-2 for an average of 6 hours.

Concerning the staff, 45 health workers entered the facility: 7 doctors, 13 nurses and 25 health workers. Of these, $15.55 \%$ are women, the remaining $84.45 \%$ are men.

The average age of female staff is 32.57 years, while the average age of male staff is 38.55 years.

The average age of doctors is 37.71 years, nurses is 42.16 years, and health workers is 36.57 years.

The medical staff entering the military field hospital held the following six-hour shifts, within the six hours doctors, nurses and health workers carried out different types of actions, from diagnostics to the administration of therapy, withdrawals and assistance to non-ambulatory staff to go to the toilets as shown in the table (Table 2).

Table 2. Workshift program

\begin{tabular}{|c|c|c|}
\hline Workshift & $\begin{array}{c}\text { Health personnel } \\
\text { employed } \\
\text { in the dirty area }\end{array}$ & $\begin{array}{c}\begin{array}{c}\text { Duration of } \\
\text { employment } \\
\text { in the dirty area }\end{array} \\
\end{array}$ \\
\hline From 08:00 & 1 physician & \multirow{3}{*}{6 hours } \\
\hline a.m. & 2 nurses & \\
\hline to $14: 00$ p.m. & $\begin{array}{c}2 \text { health operators } \\
1 \text { physician }\end{array}$ & \\
\hline $\begin{array}{l}\text { From } 14: 00 \\
\text { to } 20: 00 \text { p.m. }\end{array}$ & $\begin{array}{l}1 \text { Director of the } \\
\text { Hospital } \\
2 \text { nurses }\end{array}$ & \multirow[t]{2}{*}{6 hours } \\
\hline & 2 health operators & \\
\hline $\begin{array}{l}\text { From 20:00 } \\
\text { p.m. } \\
\text { to 2:00 a.m. }\end{array}$ & $\begin{array}{c}2 \text { nurses } \\
2 \text { health operators }\end{array}$ & 6 hours \\
\hline $\begin{array}{l}\text { From 02:00 } \\
\text { to 08:00 a.m. }\end{array}$ & $\begin{array}{c}2 \text { nurses } \\
2 \text { health operators }\end{array}$ & 6 hours \\
\hline
\end{tabular}

The table describes the period, the duration and the type of health personnel entered and stay in the dirty area at risk COVID-19 are reported.

The off-duty personnel remained available and ready to work 24 hours per day, since, being a military field hospital, the tents used for resting were just a few tens of meters away.

The medical staff within the six hours inside the dirty area also provided a psychological assistance, talking to the hospitalized staff trying to treat the psyche as well as the physical of the patient (Figure 6).

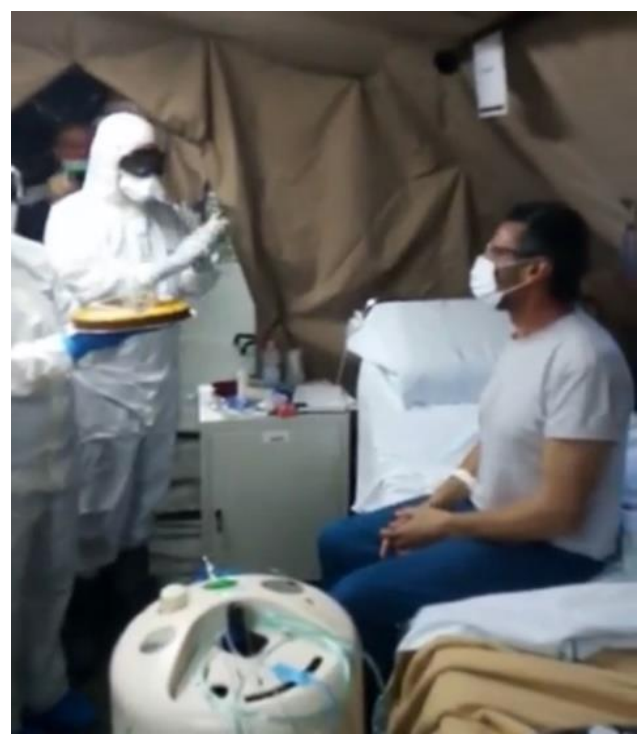

Figure 6. A COVID-19 patient celebrating his birthday with the medical staff on duty

All the health care staff tested negative for swabs, before the arrival in Piacenza, 15 days after the first patient entered and 30 days immediately after the exit of the last patient and the logistic staff of the base resulted negative. In total out of 86 
tampons carried out between the medical and logistic staff, all were negative.

Concerning the disinfection procedures, on the first day of reuse of PPE personal protective equipment (goggles), a 5\% sodium hypochlorite solution in which the goggles were left for 10 minutes was used to clean up the PPE.

However, the staff reported tearing, redness of the eyes, eye discomfort, therefore, from day two to the end of the mission the alcohol-based disinfection was successfully applied (without reported discomfort and with all negative test).

As a result of these problems reported by health personnel, it was decided to opt for the solution provided for by the WHO and produced by the Military Pharmaceutical Chemical Plant in Florence with the certainty that the alcohol, once it had performed its virucidal function, would then escape without causing any problems for the operators.

The choice was successful, since there was no longer any evidence of toxicity on the part of healthcare personnel. However, a limit of four times the reuse of protective goggles has been set to prevent any erosion of plastic parts.

At each washing, the cleaners have marked the goggles so that it is easy to identify when the fourth wash is reached.

The COVID-19 military field hospital in Piacenza was the first COVID-19 health facility in Italy to have all its staff negative for swabbing to detect the presence of COVID-19.

\section{CONCLUSIONS}

The Military Field Hospital of Piacenza was called to intervene at the height of the crisis in the second city of Italy most affected by COVID-19 in relation to the population [19]. In this contest without negative pressure systems, but correctly designed, together with the adoption of remediation protocols for personnel leaving the dirty area, based on the scientific literature (in the absence of NATO protocols specific to the COVID-19 need) has allowed to reduce to zero the contagion among health workers and to assist at the same time 50 COVID-19 patients.

The result obtained first in Italy for the absence of contagion among health workers and among the first in the world for type of structure shows how a correct design, a correct use of PPE and the application of the right remediation procedures that take into account the correct concentration and duration of treatment, can cancel the risk of contagion among health workers and not.

Although full-face visor [20] and full-face snorkel mask [21] have been suggested for healthcare workers at high risk, PPE in this study included Tyvek overalls with hood, protection class III, shoe covers, protection class III, nitrile gloves, surgical gloves size 8 and $1 / 2$.

Our results show that the correct design of the military field hospital, combined with a correct use of PPE and disinfectant solutions, can guarantee the total safety of the medical personnel operating in the military field facilities and to provide to the reuse of effective prevention devices in the absence of them, even in emergency situation. In particular, the WHO formulation produced by the Military Chemical and Pharmaceutical Plant, based on the alcohol-based solution resulted more acceptable by personnel, compared to the hypochlorite-based one.

Gheisari et al. [22] point out possible skin reaction to nonglove PPE, including facial dermatitis. Moreover, behavioral considerations must be considered, as well as the impact on personal protective equipment use [23].

Although inhalation of hypochlorite can lead only to mild irritation of the upper airways and corneal injuries from ocular exposure are generally mild with burning discomfort and superficial disturbance of the corneal epithelium with recovery within 1 or 2 days, with higher concentration solutions, severe eye irritation can occur [24]. Moreover, in addition to discomfort and potential toxicity, the use of hypochloritebased solutions and consequent ocular irritation can mask potential ocular manifestations of COVID-19 that have been suggested as one of the first symptoms of the contraction of the infection [25]. Therefore, the use of alcohol-based solution could be considered for larger studies aimed to general validated protocols and guidelines.

In anticipation of a third wave of infections [26], where new unknown and more aggressive variants of the virus [27] could make the new vaccines ineffective [28, 29], the approval of these protocols and their extension to different nations, could favor the birth of different temporary COVID-19 field hospitals. Other COVID-19 field hospitals have been built in Italy $[30,31]$. In particular, a COVID-19-only field hospital was rapidly set up in Bergamo, meeting the standards for severe acute respiratory infection treatment centers [31]. Among six European countries (UK, France, Spain, Italy, Belgium and Sweden), evaluated in a review for the civilmilitary cooperation in the early response to the COVID-19 pandemic, 'Deployment of military (field) hospitals to augment local capacity' returned the second most frequent elicitation. France returned the highest category elicitation (25 times), followed by Italy (9 times), Spain (5 times) and Sweden (1 time), whereas UK and Belgium did not elicit this category [32]. Moreover, Spain and Italy recorded the most frequent elicitations of the most frequent category elicited by the search results ('Allocation of military capability to national response') [32]. In Italy on 1 March 2021, a General of the Army Corps was appointed Extraordinary Commissioner for the implementation and coordination of the containment and contrast measures of the epidemiological emergency COVID-19 and for the execution of the national vaccination campaign [33]. The latter is successful ongoing with $66,43 \%$ of the population over 12 who have completed the vaccination cycle at 2021.08.18 [34]. However, in the period July-August 2021 an increase of infections registered in Italy has been observed [35], probably due to the Delta variant, becoming the dominant variant in England by late May, due to partial immune escape [36]. In particular, a single dose vaccination is not sufficiently protective [37] and the Delta variant has a significantly higher transmission capacity than the Alpha variant [38].

Data obtained in Italy (October 2020 - March 2021) show that the introduction of the UK Alpha variant, corresponded to the second relevant increase of infections registered in Italy during the second epidemic wave [39], when the Military field hospital of Aosta was built [40].

In the present work, the "h shape "Field hospital has proven to be efficient against COVID-19 pandemic, also thanks to the sanitation protocol adopted, in order to reduce risk for medical personnel.

In conclusion, temporary COVID-19 field hospitals would prevent the overcrowding of hospitals forced to neglect patients with other non-COVID-19 diseases and in a more difficult context, they could become the only hope to accommodate a surplus of infected patients without risk for medical health personnel. 


\section{ACKNOWLEDGMENT}

This work is supported by the AUSL of Piacenza for the logistic support and coordination in the management of patients and by all the doctors and all the nurses and health workers employed within the hospital.

\section{REFERENCES}

[1] Coronaviridae Study Group of the International Committee on Taxonomy of Viruses. (2020). The species severe acute respiratory syndrome-related coronavirus: Classifying 2019-nCoV and naming it SARS-CoV-2. Nature Microbiology, 5(4): 536-544. https://doi.org/10.1038/s41564-020-0695-z

[2] WHO. (2020). Available from: https://www.who.int/dg/speeches/detail/who-directorgeneral-s-opening-remarks-at-the-media-briefing-oncovid-19---11-march-2020

[3] Worldometer. Italy Coronavirus: 128,948 Cases and 15,887 Deaths. (2020). Available from: https://www.worldometers.info/coronavirus/country/ital $\mathrm{y} /$.

[4] Corman, V.M., Muth, D., Niemeyer, D., Drosten, C. (2018). Hosts and sources of endemic human coronaviruses. Advances in Virus Research, 100: 163 188. https://doi.org/10.1016/bs.aivir.2018.01.001

[5] Andersen, K.G., Rambaut, A., Lipkin, W.I., Holmes, E.C., Garry, R.F. (2020). The proximal origin of SARSCoV-2. Nature medicine, 26(4): 450-452. https://doi.org/10.1038/s41591-020-0820-9

[6] Shereen, M.A., Khan, S., Kazmi, A., Bashir, N., Siddique, R. (2020). COVID-19 infection: Origin, transmission, and characteristics of human coronaviruses. Journal of Advanced Research, 24: 91-98 https://doi.org/10.1016/j.jare.2020.03.005

[7] Kumar, S., Maurya, V.K., Prasad, A.K., Bhatt, M.L., Saxena, S.K. (2020). Structural, glycosylation and antigenic variation between 2019 novel coronavirus (2019-nCoV) and SARS coronavirus (SARS-CoV). Virusdisease, 31(1): 13-21. https://doi.org/10.1007/s13337-020-00571-5

[8] Ling, Y., Xu, S.B., Lin, Y.X., Tian, D., Zhu, Z.Q., Dai, F.H., Lu, H.Z. (2020). Persistence and clearance of viral RNA in 2019 novel coronavirus disease rehabilitation patients. Chinese Medical Journal, 133(9): 1039. https://doi.org/10.1097/CM9.0000000000000774

[9] Zhai, P., Ding, Y., Wu, X., Long, J., Zhong, Y., Li, Y. (2020). The epidemiology, diagnosis and treatment of COVID-19. International Journal of Antimicrobial Agents, 55(5): 105955. https://doi.org/10.1016/j.ijantimicag.2020.105955

[10] Gatto, M., Bertuzzo, E., Mari, L., Miccoli, S., Carraro, L., Casagrandi, R., Rinaldo, A. (2020). Spread and dynamics of the COVID-19 epidemic in Italy: Effects of emergency containment measures. Proceedings of the National Academy of Sciences, 117(19): 10484-10491. https://doi.org/10.1073/pnas.2004978117

[11] Ho, L.T., Chan, K.K., Chung, V.C., Leung, T.H. (2020). Highlights of traditional Chinese medicine frontline expert advice in the China national guideline for COVID19. European Journal of Integrative Medicine, 36: 101116. https://doi.org/10.1016/j.eujim.2020.101116
[12] NATO, NATO STANDARD AJP-4.10 Allied Doctrine for Medical Support Edition C 11 September (2019). Available

from: https://assets.publishing.service.gov.uk/government/upl oads/system/uploads/attachment_data/file/922182/doctri ne_nato_med_spt_ajp_4_10.pdf

[13] UnitedNation, Medical Support Manual for United Nations Peacekeeping Operations, 2nd Edition (1999). Available from: https://reliefweb.int/sites/reliefweb.int/files/resources/D 196C0B0FF3A637BC1256DD4004983B9-dpkomedical-1999.pdf

[14] Covid, C.D.C., Team, R., COVID, C., Team, R., COVID, C., Team, R., Walters, M. (2020). Characteristics of health care personnel with COVID-19-United States, February 12-April 9, 2020. Morbidity and Mortality Weekly Report, 69(15): 477-481. https://doi.org/10.15585/mmwr.mm6915e6

[15] Bauchner, H., Fontanarosa, P.B., Livingston, E.H. (2020). Conserving supply of personal protective equipment-a call for ideas. Jama, 323(19): 1911-1911. https://doi.org/10.1001/jama.2020.4770

[16] Van Doremalen, N., Bushmaker, T., Morris, D.H., Holbrook, M.G., Gamble, A., Williamson, B.N., Munster, V.J. (2020). Aerosol and surface stability of SARS-CoV2 as compared with SARS-CoV-1. New England Journal of Medicine, 382(16): 1564-1567. https://doi.org/10.1056/NEJMc2004973

[17] Kampf, G., Todt, D., Pfaender, S., Steinmann, E. (2020). Persistence of coronaviruses on inanimate surfaces and their inactivation with biocidal agents. Journal of Hospital Infection, 104(3): 246-251. https://doi.org/10.1016/j.jhin.2020.01.022

[18] Fathizadeh, H., Maroufi, P., Momen-Heravi, M., Dao, S., Ganbarov, K., Pagliano, P., Kafil, H.S. (2020). Protection and disinfection policies against SARS-CoV2 (COVID-19). Le Infezioni in Medicina, 28(2): 185-191. http://www.ncbi.nlm.nih.gov/pubmed/32275260.

[19] Corrieredellasera. (2020). Available from: https://www.corriere.it/cronache/20_aprile_23/recordmorti-piacenzaqui-stata-un-ecatombe-82ecc3ca-859a11ea-b71d-7609e1287c32.shtml.

[20] Heij, R., Steel, A.G., Young, P.J. (2020). Testing for coverage from personal protective equipment: Public Health England's guidance does not protect healthcare workers from droplet spray. Anaesthesia, 75(7): 966-967. https://doi.org/10.1111/anae.15079

[21] Greig, P.R., Carvalho, C., El-Boghdadly, K., Ramessur, S. (2020). Safety testing improvised COVID-19 personal protective equipment based on a modified full-face snorkel mask. Anaesthesia, 75(7): 970-971. https://doi.org/10.1111/anae.15085

[22] Gheisari, M., Araghi, F., Moravvej, H., Tabary, M., Dadkhahfar, S. (2020). Skin reactions to non-glove personal protective equipment: an emerging issue in the COVID-19 pandemic. J Eur Acad Dermatol Venereol, 34(7): e297-e298. https://doi.org/10.1111/jdv.16492

[23] Kantor, J. (2020). Behavioral considerations and impact on personal protective equipment use: Early lessons from the coronavirus (COVID-19) pandemic. Journal of the American Academy of Dermatology, 82(5): 1087-1088. https://doi.org/10.1016/j.jaad.2020.03.013

[24] Slaughter, R.J., Watts, M., Vale, J.A., Grieve, J.R., Schep, L.J. (2019). The clinical toxicology of sodium 
hypochlorite. Clinical Toxicology, 57(5): 303-311. https://doi.org/10.1080/15563650.2018.1543889

[25] Li, J.P.O., Lam, D.S.C., Chen, Y., Ting, D.S.W. (2020). Novel Coronavirus disease 2019 (COVID-19): The importance of recognising possible early ocular manifestation and using protective eyewear. $\mathrm{Br} \mathrm{J}$ Ophthalmol, 104(3): 297-298. https://doi.org/10.1136/bjophthalmol-2020-315994

[26] O'Dowd, A., (2020). Covid-19: Avoid indoor mixing over Christmas or risk third wave, warns iSAGE. BMJ, 371: m4832. https://doi.org/10.1136/bmj.m4832

[27] Wibmer, C.K., Ayres, F., Hermanus, T., Madzivhandila, M., Kgagudi, P., Oosthuysen, B., Moore, P.L. (2021). SARS-CoV-2 501Y. V2 escapes neutralization by South African COVID-19 donor plasma. Nature Medicine, 27(4): 622-625. https://doi.org/10.1136/bmj.m4857

[28] Koyama, T., Weeraratne, D., Snowdon, J.L., Parida, L. (2020). Emergence of drift variants that may affect COVID-19 vaccine development and antibody treatment. Pathogens, 9(5):

324. https://doi.org/10.3390/pathogens9050324

[29] Oliver, S.E., Gargano, J.W., Marin, M., Wallace, M., Curran, K.G., Chamberland, M., Dooling, K. (2020). The advisory committee on immunization practices' interim recommendation for use of Pfizer-BioNTech COVID-19 vaccine-United States, December 2020. Morbidity and Mortality Weekly Report, 69(50): 1922. https://doi.org/10.15585/mmwr.mm6950e2

[30] https://www.ospedale.perugia.it/notizie/ospedale-dacampo-allestito-dallesercito-accanto-al-santa-mariadella-misericordia.

[31] Spagnolello, O., Rota, S., Valoti, O.F., Cozzini, C., Parrino, P., Portella, G., Langer, M. (2020). Bergamo field hospital confronting COVID-19: Operating instructions. Disaster Medicine and Public Health Preparedness, pp. 1-3. https://doi.org/10.1017/dmp.2020.447

[32] Gad, M., Kazibwe, J., Quirk, E., Gheorghe, A., Homan, Z., Bricknell, M. (2021). Civil-military cooperation in the early response to the COVID-19 pandemic in six European countries. BMJ Mil Health. https://doi.org/10.1136/bmjmilitary-2020-001721
[33] https://www.governo.it/it/dipartimenti/commissariostraordinario-lemergenza-covid-19/cscovid19commissario/14419.

[34] https://www.governo.it/it/cscovid19/report-vaccini/.

[35] https://www.epicentro.iss.it/en/coronavirus/sars-cov-2dashboard.

[36] Mishra, S., Mindermann, S., Sharma, M. et al. (2021). Changing composition of SARS-CoV-2 lineages and rise of Delta variant in England. EClinicalMedicine, 39: 101064. https://doi.org/10.1016/j.eclinm.2021.101064

[37] Li, X.N., Huang, Y., Wang, W., Jing, Q.L., Zhang, C.H., Qin, P.Z., Zhong, N.S. (2021). Effectiveness of inactivated SARS-CoV-2 vaccines against the Delta variant infection in Guangzhou: a test-negative casecontrol real-world study. Emerging Microbes \& Infections, (just-accepted), 10(1): 1751-1759. https://doi.org/10.1080/22221751.2021.1969291

[38] Xia, F., Yang, X., Cheke, R.A., Xiao, Y. (2021). Quantifying competitive advantages of mutant strains in a population involving importation and mass vaccination rollout. Infectious Disease Modelling, 6: 988-996. https://doi.org/10.1016/j.idm.2021.08.001

[39] Lai, A., Bergna, A., Menzo, S. et al. (2021). Circulating SARS-CoV-2 Variants in Italy, October 2020-March 2021. Virology Journal, 18: 168. https://doi.org/10.1186/s12985-021-01638-5

[40] https://www.ansa.it/valledaosta/notizie/2020/11/30/covi d-ad-aosta-e-pronto-ospedale-da-campodellesercito_ba3fe409-7fac-4706-bee3a0cfe5e6e920.html.

\section{NOMENCLATURE}

COVID-19 2019 novel coronavirus disease

NATO North Atlantic Treaty Organization

PPE personal protective equipment

UN United Nation

SARS-CoV- severe acute respiratory syndrome

2

WHO World Health Organization 